\title{
PANDEMIA E A EDUCAÇÃO NO ESTADO DO TOCANTINS: elementos para avaliar o contexto
}

\author{
Sandra Fernandes Leitel \\ Fernando Tavares Junior ${ }^{2}$ \\ Catharina da Cunha Glória ${ }^{3}$
}

\begin{abstract}
RESUMO
A pandemia trouxe vários desafios para a população brasileira. Em particular, faz-se necessário compreender como esse fenômeno impacta a educação e quais ações tomadas para seu enfrentamento. O objetivo é apontar as ações tomadas no âmbito da Secretaria Estadual de Educação do Tocantins no enfrentamento da pandemia e as ações previstas para retomada das atividades presenciais escolares. Rrealizouse um recorte temporal de junho a julho de 2020 sobre os municípios do Tocantins, organizando informações sobre as escolas, sobre a pandemia e ações do Estado para seu enfrentamento. O texto aponta uma primeira forma de avaliar as ações dos órgãos responsáveis pela educação e acompanhar os impactos da pandemia no sistema de educação de um estado, possível de ser replicado para outras regiões.
\end{abstract}

Palavras-chave: Avaliação Escolar. Estatísticas Educacionais. Pandemia.

\section{PANDEMICS AND EDUCATION IN THE STATE OF TOCANTINS:}

\section{elements to Assess Context}

\begin{abstract}
The pandemic brought several challenges to the Brazilian population. In particular, it is necessary to understand how this phenomenon impacts education and what actions are taken to face it. The objective is to point out the actions taken within the scope of the State Department of Education of Tocantins to fight the pandemic and the actions planned for the resumption of in-person school activities. A time frame was carried out from June to July 2020 on the municipalities of Tocantins, organizing information about schools, the pandemic and State actions to fight it. The text points to a first way of evaluating the actions of the bodies responsible for education and monitoring the impacts of the pandemic on the education system of a state, which can be replicated in other regions.
\end{abstract}

Keywords: School evaluation. Educational Statistics. Pandemic.

\footnotetext{
1 Doutorado em Educação, Unicamp; Universidade Estadual de Campinas; Grupo de Estudos e Pesquisas em Política e Avaliação Educacional; Orcid iD: https://orcid.org/0000-0002-92136508; E-mail: sfleite@unicamp.br

2 Pós-Doutorado em Educação. Universidade Federal de Juiz de Fora (DCSO - ICH - UFJF). Bolsista de Produtivodade em Pesquisa - CNPq PQ2. Grupo de Pesquisa EQUITY - Dimensões da Igualdade. Orcid iD: https://orcid.org/0000-0001-7892-4017; E-mail: ftavares@caed.ufj.br

3 Graduanda no curso de bacharelado e licenciatura em Dança, Unicamp; Bolsista de Iniciação Científica do CNPq; Orcid iD: https://orcid.org/0000-0001-7758-6335 E-mail: catharinacgloria@gmail.com
} 


\title{
PANDEMIAS Y EDUCACIÓN EN EL ESTADO DE TOCANTINS: \\ elementos para evaluar el contexto
}

\begin{abstract}
RESUMEN
La pandemia trajo varios desafíos a la población brasileña. En particular, es necesario comprender cómo impacta este fenómeno en la educación y qué acciones se toman para enfrentarlo. El objetivo es señalar las acciones tomadas en el ámbito del Departamento de Educación del Estado de Tocantins para combatir la pandemia y las acciones previstas para la reanudación de las actividades escolares presenciales. Se realizó un cronograma de junio a julio de 2020 en los municipios de Tocantins, organizando información sobre escuelas, la pandemia y acciones del Estado para combatirla. El texto apunta a una primera forma de evaluar las acciones de los órganos responsables de la educación y monitorear los impactos de la pandemia en el sistema educativo de un estado, que se puede replicar en otras regiones.
\end{abstract}

Palabras clave: Evaluación escolar. Estadísticas educativas. Pandemia.

\section{INTRODUÇÃO}

A disseminação do novo coronavírus e o combate da doença mobilizou uma grande cadeia de ações, como a execução de intervenções nãofarmacológicas, estudos sobre os sintomas, formas de contágio e tratamentos, além da incansável busca por medicamentos e vacinas eficientes. Contudo, faz-se também necessária a compreensão da pandemia ${ }^{4}$ como um fenômeno social, pois a transmissão do vírus em suas variadas medidas de enfrentamento e seus efeitos associam-se às relações e estruturas sociais, cujas fragilidades são agravadas durante as crises que atravessam e sucedem uma pandemia.

O acesso a materiais de higienização, serviços de saúde e saneamento básico, possibilidade de isolamento social e adaptação ao trabalho remoto, reserva de recursos financeiros e bens de consumo são premissas, por vezes invisibilizadas, para a real aplicabilidade de tais medidas preventivas. Para somar aos fatores de desigualdade, Carvalho et al. (2020) apresentam um relatório acerca da distribuição dos fatores de risco no Brasil. Segundo dados trazidos pelas autoras, comorbidades que podem levar ao quadro grave da

${ }_{4}^{4}$ FIOCRUZ. Pandemia: O que é uma pandemia? Disponível em:

https://www.bio.fiocruz.br/index.php/br/noticias/1763-o-que-e-uma-pandemia. Acesso em: 27 jul. 2021. 
COVID-19 encontram-se proporcionalmente muito mais presentes em pessoas que declararam ter frequentado apenas o ensino fundamental.

Apesar da possibilidade de que a doença atinja de forma distinta as diferentes parcelas populacionais, o adoecimento em massa da classe trabalhadora gera consequências dentro de toda a cadeia organizacional. Em uma pandemia, o vírus "na ausência de segregação absoluta e isolamento social 'entre categorias', ele potencialmente atinge todos os grupos" (FIGUEIREDO SANTOS, 2020, p. 4). Trata-se assim do desprendimento da ideia de individualização à coletividade da doença, estando diretamente relacionada ao contato e trânsito territorial, ou seja, à construção do dinamismo social no espaço.

No Brasil, compreendendo seu tamanho continental, há também uma variação no avanço da COVID-19. Para esse artigo voltamos o olhar para o Estado do Tocantins. A proposta tem como objetivo registrar as ações tomadas no âmbito da Secretaria Estadual de Educação do Tocantins no enfrentamento da pandemia durante o factível ano de 2020 e as ações previstas para retomada das atividades presenciais em 2021. Esse recorte não pretende esgotar o tema, mas registrar, recuperar as ações implementadas, as dificuldades enfrentadas e os impactos na educação do Estado, considerando em especial a oferta de uma educação pública e a garantia ao direito à educação.

Foi feita uma pesquisa qualitativa com dados documentais e bibliográficos em sites e portais de órgãos que trataram da temática. Podemos citar a Secretaria Estadual de Educação do Tocantins, o Ministério Público do Estado do Tocantins, o Conselho Estadual de Educação do Estado do Tocantins entre outros.

Segundo o Boletim epidemiológico número 308 com Notificações para a Covid-19, publicado em 17 de janeiro de 2021 eram contabilizados no estado do Tocantins 96.390 casos confirmados, 1313 óbitos, 236 pessoas hospitalizadas com a Covid-19. O boletim detalha a situação do estado do Tocantins, 
A Secretaria de Estado da Saúde (SES) informa que neste domingo, 17 de janeiro, foram contabilizados 335 novos casos confirmados para Covid-19. Deste total, 102 foram registrados nas últimas 24 horas e o restante por exames coletados em dias anteriores e que tiveram seus resultados liberados na data de ontem. Desta forma, hoje o Tocantins registra um total de 309.959 pessoas notificadas com a Covid-19 e acumula 96.390 casos confirmados da doença. Destes, 85.249 pacientes estão recuperados e 9.828 estão ainda ativos (em isolamento domiciliar ou hospitalar), além de 1.313 óbitos (TOCANTINS, 2021).

Para quem conhece a rotina administrativa da educação, sabe que uma parte importante do planejamento escolar é a definição do calendário escolar, o cumprimento das normativas legais e o planejamento de todo o ano letivo. Um exemplo é a garantia do cumprimento da carga horária e dos dias letivos. Parece simples, mas trata-se de um trabalho meticuloso que precisa de atenção e de conciliar toda e qualquer possibilidade de suspensão de aula, seja para recessos, férias escolares entre outras possibilidades. Em síntese definido o calendário escolar e o planejamento a ser executado, o ano letivo começa e essa prática ano a ano se repete. Em 2020 não deveria ter sido diferente. Embora o noticiário já se alertava para o risco de a pandemia ter proporções globais não se sabia, se de fato já era possível prever o que deveria ser feito. Podemos afirmar que o Brasil teve a oportunidade de assistir o aumento da disseminação da Covid-19 no mundo. Fechamentos de cidades inteiras, a obrigatoriedade para o uso de máscaras, isolamento social, entre outras ações. Em um primeiro momento, essas ações pareciam extremamente distantes da realidade brasileira, acreditamos, aqui fazendo referências às opções governamentais, que não tínhamos que nos preocupar. De certa forma, o vírus não chegaria ao País. Negacionismo, desconhecimento de vivermos em um mundo globalizado, conectado entre outros ensaios que podemos pensar. O fato é que para muitos o vírus estava bem longe e não havia o que temer. Mas a realidade se impôs e nas inúmeras bagagens de muitos, o vírus desembarcou no País e não teve dó ou compreensão com nossa ignorância ou com nossa arrogância diante da crise 
que já anunciava fazia tempos. Rapidamente o vírus se espalhou por todo o País ao longo de 2020.

Em um País como o Brasil, em que as mazelas da educação são seculares, é e será difícil compreender esse momento ímpar, sem dúvida histórico e que marcará a educação brasileira por décadas. Mas vamos fazer um retrato, um recorte olhando para o Estado brasileiro do Tocantins. Como esse estado se organizou? Como interpretou a Pandemia no estado e nos seus municípios? Como se articulou diante de um cenário tão adverso para toda a comunidade escolar? É importante ressaltar, que a educação foi bastante impactada com a suspensão das atividades escolares. Propomos resgatar e acompanhar os impactos desse afastamento das atividades escolares, usando um recorte territorial no Estado do Tocantins e um recorte temporal do ano de 2020 e as primeiras ações já tomadas em 2021.

\section{O ESTADO DO TOCANTINS}

Segundo dados do IBGE Cidades5, o Estado do Tocantins tem uma população estimada em 2020 de 1.590.248 pessoas. Dados do último censo realizado em 2010 apontavam 1.383.445 pessoas em todo o Estado. A população residente considerada por situação de domicílio era em sua maioria urbana, mas dados do Censo de 2010 registravam uma parcela da população em áreas rurais.

Considerando os dados do Índice de Desenvolvimento da Educação Básica (IDEB) ${ }^{6}$ para os Anos iniciais do ensino fundamental (Rede pública) o índice do estado era de 5,4 e para os Anos finais do ensino fundamental (Rede pública) o índice era de 4,5. Comparado com outros estados, segundo o site do IBGE Cidades o Estado do Tocantins se encontrava na $27^{\circ}$ posição. A rede contemplava um total de 246.183 matrículas no ensino fundamental e 63.384 matrículas no ensino médio. Olhando para o Índice de Desenvolvimento

\footnotetext{
5 IBGE. IBGE Cidades. Disponível em: https://cidades.ibge.gov.br/. Acesso em: 27 jul. 2021. 6 INEP. Índice de Desenvolvimento da Educação Básica (IDEB). Disponível em: https://www.gov.br/inep/pt-br/areas-de-atuacao/pesquisas-estatisticas-e-indicadores/ideb Acesso em: 27 jul. 2021.
} 
Humano (IDH)7, considerando o ano de 2010 o IDH do estado do Tocantins era de 0,6999. Lagares (2020) relata que para a avaliação do IDEB em 2021 a orientação vem da Portaria n. ${ }^{\circ}$ 458, de 05 de maio de 2020 que institui normas complementares necessárias ao cumprimento da Política Nacional de Avaliação da Educação Básica (SAEB) que normatiza as mudanças previstas para a próxima edição do SAEB e que exigirão atenção redobrada (LAGARES, 2020).

No portal da Secretaria da Educação, Juventude e Esportes do Estado do Tocantins encontramos no link "Ações do Governo" um link intitulado "Coronavírus" (TOCANTINS, 2020). Nele é possível conhecer as ações implementadas pelo governo do Estado, os decretos governamentais e uma série de links de notícias sobre a temática que envolvem a pandemia. Seguindo as orientações da Organização Mundial da Saúde (OMS) e do Ministério da Saúde, o então governador do estado do Tocantins, Mauro Carlesse instituiu um Comitê de Crise para prevenção da Covid-19. Uma das primeiras medidas tomadas foi a suspensão das aulas da rede estadual de ensino.

No Portal da Secretaria da Educação, Juventude e Esporte do Governo do Estado do Tocantins na aba "Ações do Governo" encontramos todas as informações tomadas e ações que foram sendo incorporadas ao longo de todo o ano letivo de 2020 (TOCANTINS, 2020). Além da suspensão das aulas na rede estadual de ensino e reconhecendo que o impacto no acesso a alimentação dos alunos seria fortemente impactado com a suspensão das aulas, o governo determinou a entrega de kits de alimentos para cada aluno da rede escolar. A entrega dos kits teve início no mês de março de 2020. No Portal é possível ter acesso a lista de escolas que receberam os kits de alimentos na primeira e segunda etapa em foram distribuídas, as informações aos estudantes sobre a entrega dos kits de alimentos, todos os decretos expedidos no período, os contratos voltados especificamente ao coronavírus

\footnotetext{
7 UNDP. O conceito de Desenvolvimento Humano. Disponível em:

https://www.br.undp.org/content/brazil/pt/home/idh0/conceitos/o-que-e-o-idh.html. Acesso em: 27 jul. 2021
}

Revista Exitus, Santarém/PA, Vol. 11, p. 01 - 25, e020192, 2021. 
e um link com perguntas e respostas sobre a suspensão das aulas na rede estadual para prevenção ao coronavírus. Embora não tenha se mantido atualizado com novas informações como se poderia esperar encontrar neste espaço, ele levanta as primeiras dúvidas que surgiram diante do cenário de incertezas que foi a marca do ano letivo de 2020.

Ao longo do ano de 2020 foram sete decretos governamentais expedidos pelo governo do Estado do Tocantins. Sendo eles:

- DECRETO N. ${ }^{\circ} 6.065$, DE 13 DE MARÇO DE 2020. Determina ação preventiva para o enfrentamento do COVID-19 - novo Coronavírus. (...).

- DECRETO NO 6.069, DE 18 DE MARÇO DE 2020. Declara facultativo o ponto na data que especifica. (...)

- DeCReto legislativo № 176, DE 24 DE MARÇO De 2020. Reconhece, para os fins do art. 65 da Lei Complementar $n^{\circ} 101$, de 4 de maio de 2000, a ocorrência do estado de calamidade pública, nos termos da solicitação do Governador do Estado encaminhada por meio da Mensagem n²1, de 23 de março de 2020.

- DECRETO NO 6.099, DE 28 DE MAIO DE 2020. Dispõe sobre a prorrogação de prazos relativos à suspensão de atividades educacionais e à jornada de trabalho, na forma que especifica, e adota outras providências. (...).

- DECRETO NO 6.112, DE 29 DE JUNHO DE 2020. Dispõe sobre a prorrogação de prazos relativos à suspensão de atividades educacionais e à jornada de trabalho, na forma que especifica, e adota outras providências. (...).

- DECRETO no 6.128, de 31 de julho de 2020. Dispõe sobre a prorrogação de prazos relativos à suspensão de atividades educacionais e à jornada de trabalho, na forma que especifica, e adota outras providências. (...)

O primeiro decreto foi expedido em março de 2020, o Decreto n. ${ }^{\circ} 6.065$. Neste decreto as atividades educacionais nas unidades escolares da rede pública estadual de ensino e na Universidade Estadual do Tocantins (UNITINS) foram suspensas no período de 16 a 20 de março de 2020, conforme o artigo $1^{\circ}$. No dia 18 de março de $2020 \mathrm{com}$ a proximidade das festividades Cristã de São José, padroeiro da capital do Estado, decretou ser o dia 20 de março de 2020, facultativo o ponto nas unidades da administração direta e indireta do Poder Executivo sediados em Palmas, ações determinadas pelo Decreto n. ${ }^{\circ}$ 6069/2020. Em 24 de março de 2020 o Decreto Legislativo n. ${ }^{\circ}$ 176, reconheceu a ocorrência de estado de calamidade pública, de acordo com a normatização vigente. Em 28 de maio de 2020, o Decreto n. ${ }^{\circ} 6.099$ dispôs sobre 
a prorrogação de prazos relativos à suspensão das atividades educacionais. Foram mantidas suspensas as atividades educacionais presenciais em estabelecimentos de ensino com sede no Estado do Tocantins, sendo eles públicos ou privados até a data de 30 de junho de 2020. O artigo $2^{\circ}$ determinou "aos chefes de cada Poder Executivo Municipal, aos órgãos reguladores do Sistema de Ensino e aos responsáveis por mantenedoras das instituições públicas e privadas é [foi] recomendada a adoção de medidas complementares necessárias ao cumprimento do artigo $1^{\circ}$ deste decreto". 0 artigo também cita a adoção como parâmetro a Medida Provisória Federal n. 934 de abril de 2020 e a Resolução CEE/TO n 105 de abril de 2020, no sentido de reorganizar seus calendários.

Em junho de 2020 foi expedido o Decreto $n .^{\circ} 6112$, o artigo $1^{\circ}$ manteve suspensas as atividades educacionais presenciais em estabelecimentos com sede no Estado do Tocantins, público ou privado como escolas e universidades, até 31 de julho de 2020. Em 31 de julho de 2020 foi expedido o Decreto n. ${ }^{\circ}$ 6128. Neste decreto houve uma nova prorrogação da suspensão das atividades educacionais prorrogando a suspensão até 31 de agosto de 2020. A partir dessa data não há informações precisas no Portal da Seduc sobre as orientações que foram tomadas relativo ao retorno das atividades presenciais no Estado.

Durante a pandemia, $O$ isolamento social foi uma medida extremamente necessária para tentar conter a explosão do avanço da Covid-19 e, consequentemente, o colapso do Sistema Único de Saúde (SUS). Porém o fechamento das escolas trouxe muitas incertezas diante dos possiveis impactos na educação brasileira. O cumprimento do ano letivo em 2020, as condições de manutenção do processo de ensino aprendizagem diante de tantas desigualdades trouxeram novos desafios que tiveram que ser pensados rapidamente e sem muitas certezas para as possiveis decisões tomadas. Em grande medida as decisões foram sendo pautadas e resolvidas ou pelo menos encaminhadas diante do correr do tempo e do avanço da pandemia. Por outro lado, a falta de uma política governamental indutora por parte da União, efetiva e com diretrizes específicas para ações nesse momento tão 
ímpar, para se pensar a viabilidade de propostas de ensino não presencial causaram inúmeras dúvidas, incertezas e impasses para os profissionais da educação. O uso das tecnologias, por exemplo, além de todo desafio exigido para os profissionais da educação agora também para as famílias e para os alunos. Escassez de recursos, falta de acesso à internet e uma infinidade de problemas foram sendo desvelados. Se de um lado temos escolas nas quais os alunos utilizam de notebooks, tabletes e celulares e condições plenas para uma aula online nesse momento, de outro lado, temos inúmeras escolas sem internet, sem condições de seus alunos acompanharem minimamente as orientações mais básicas para esse período. Falta tudo! Uma realidade dura e cruel veio à tona. A falta de investimento na educação pública, a falta de acesso à tecnologia, a falta de formação dos professores para uso das tecnologias em sala de aula e inúmeras mazelas que foram sendo escancaradas com a pandemia. Um cenário difícil para uma parte significativa da população que depende da escola pública para o seu direito a educação.

\section{A Ações do Conselho Nacional de Educação (CNE) durante a pandemia}

Diante desse cenário o Conselho Nacional de Educação (CNE) emitiu uma série de Pareceres e Resoluções voltados para atender as demandas do período marcado pela calamidade pública. Cabe destacar as alterações no calendário escolar e ações que foram tomadas em função das especificidades trazidas pela Covid-19:

- Parecer CNE/CP n 5/2020, aprovado em 28 de abril de 2020 - Reorganização do Calendário Escolar e da possibilidade de cômputo de atividades não presenciais para fins de cumprimento da carga horária mínima anual, em razão da Pandemia da COVID-19.

- Parecer CNE/CP $n^{\circ}$ 9/2020, aprovado em 8 de junho de 2020 - Reexame do Parecer CNE/CP n०5/2020, que tratou da reorganização do Calendário Escolar e da possibilidade de cômputo de atividades não presenciais para fins de

\footnotetext{
8 MEC. Sobre o Conselho Nacional de Educação. Disponível em: http://portal.mec.gov.br/conselho-nacional-de-educacao/apresentacao Acesso em: 27 jul. 2021.
} 
cumprimento da carga horária mínima anual, em razão da Pandemia da COVID-19.

- Parecer CNE/CP n' 11/2020, aprovado em 7 de julho de 2020 - Orientações Educacionais para a Realização de Aulas e Atividades Pedagógicas Presenciais e Não Presenciais no contexto da Pandemia.

- Parecer CNE/CP n 15/2020, aprovado em 6 de outubro de 2020 - Diretrizes Nacionais para a implementação dos dispositivos da Lei $n^{\circ} 14.040$, de 18 de agosto de 2020, que estabelece normas educacionais excepcionais a serem adotadas durante o estado de calamidade pública reconhecido pelo Decreto Legislativo $n^{\circ}$ 6, de 20 de março de 2020.

- Parecer CNE/CP n 16/2020, aprovado em 9 de outubro de 2020 - Reexame do item 8 (orientações para o atendimento ao público da educação especial) do Parecer CNE/CP n 11, de 7 de julho de 2020, que trata de Orientações Educacionais para a Realização de Aulas e Atividades Pedagógicas Presenciais e Não Presenciais no contexto da pandemia.

- Parecer CNE/CP n 19/2020, aprovado em 8 de dezembro de 2020 - Reexame do Parecer CNE/CP $n^{\circ} 15$, de 6 de outubro de 2020, que tratou das Diretrizes Nacionais para a implementação dos dispositivos da Lei $n^{\circ} 14.040$, de 18 de agosto de 2020, que estabelece normas educacionais excepcionais a serem adotadas durante o estado de calamidade pública reconhecido pelo Decreto Legislativo $n^{\circ}$ 6, de 20 de março de 2020.

- Resolução CNE/CP n 2, de 10 de dezembro de 2020 - Institui Diretrizes Nacionais orientadoras para a implementação dos dispositivos da Lei $n^{\circ}$ 14.040, de 18 de agosto de 2020, que estabelece normas educacionais excepcionais a serem adotadas pelos sistemas de ensino, instituições e redes escolares, públicas, privadas, comunitárias e confessionais, durante o estado de calamidade reconhecido pelo Decreto Legislativo $n^{\circ}$ 6, de 20 de março de 2020.

- Resolução CNE/CES n 1, de 29 de dezembro de 2020 - Dispõe sobre prazo de implantação das novas Diretrizes Curriculares Nacionais (DCNs) durante a calamidade pública provocada pela pandemia da COVID-19.

O Conselho Estadual de Educação do Tocantins (CEE) ${ }^{9}$ teve importante atuação ao longo de 2020. Segundo o Informativo do CEE/TO em março de 2020 foram discutidas as demandas legais e pedagógicas da suspensão das aulas como medida contra a Covid-19. Na reunião de abril de 2020 pode-se destacar a Resolução CEE/TO n. ${ }^{\circ} 105 / 2020$ "Para atender as demandas decorrentes deste cenário regulamentou, em caráter excepcional, por meio da Resolução CEE/TO n. ${ }^{\circ}$ 105/2020 o regime especial de atividades não

\footnotetext{
9 TOCANTINS. Sobre o Conselho Estadual de Educação do Tocantins. Disponível em:
} https://cee.to.gov.br/conselho/conselho/historico/ Acesso em: 27 jul. 2021. 
presenciais como medida preventiva contra a disseminação do novo coronavírus (COVID-19)". A partir do mês de março de 2020 o CEE/TO passou a realizar suas reuniões por Web-Conferência. Foram debatidos ao logo de 2020 as questões referentes a educação na pandemia. Em julho de 2020 o Presidente do CEE/TO participou de uma live sobre recomendações às redes e sistemas de ensino em tempos de pandemia. No mês de setembro de 2020 - CEE/TO e a União dos Dirigentes Municipais da Educação do Tocantins (UNDIME) realizaram uma reunião técnica com o objetivo de orientar as redes e os sistemas municipais de ensino sobre a oferta educacional no período da pandemia. Também foram debatidas questões sobre a educação especial. A reunião de novembro de 2020 teve como foco "Educação Especial em Tempos de Pandemia" que foi discutida na $406^{\circ}$ Sessão Plenária do CEE/TO. Na reunião de dezembro de 2020 foram apresentados estudos pedagógicos e pesquisas publicadas por servidores do Conselho Estadual de Educação do Tocantins.

\section{O Programa Educação Conectada}

O Estado do Tocantins possui 1.608 escolas de educação básica em 139 municípios, segundo os dados de 2019. Foram registradas 397.631 matrículas de educação básica. Selecionadas as escolas nos microdados do Censo Escolar de 2019 (INEP, 2021) dos municípios que tiveram pelo menos uma medida de download no programa Educação Conectada lo dado TCP_DOWN_MBPS mede algum download entre abril de 2019 e janeiro de 2021) (MEC, 2021), indicando que a escola possui internet. Foram encontrados 127 municípios com 528 escolas e 215 mil matrículas. Dessas 528 escolas, foram selecionadas aquelas que possuem acesso à Internet para uso dos alunos (microdados do Censo Escolar de 2019 com a informação IN_INTERNET_ALUNOS). Foram encontrados 100 municípios com 250 escolas e 112 mil matrículas. 
FIGURA 1 - Repartição dos municípios do Tocantins com escolas com acesso à internet para os alunos

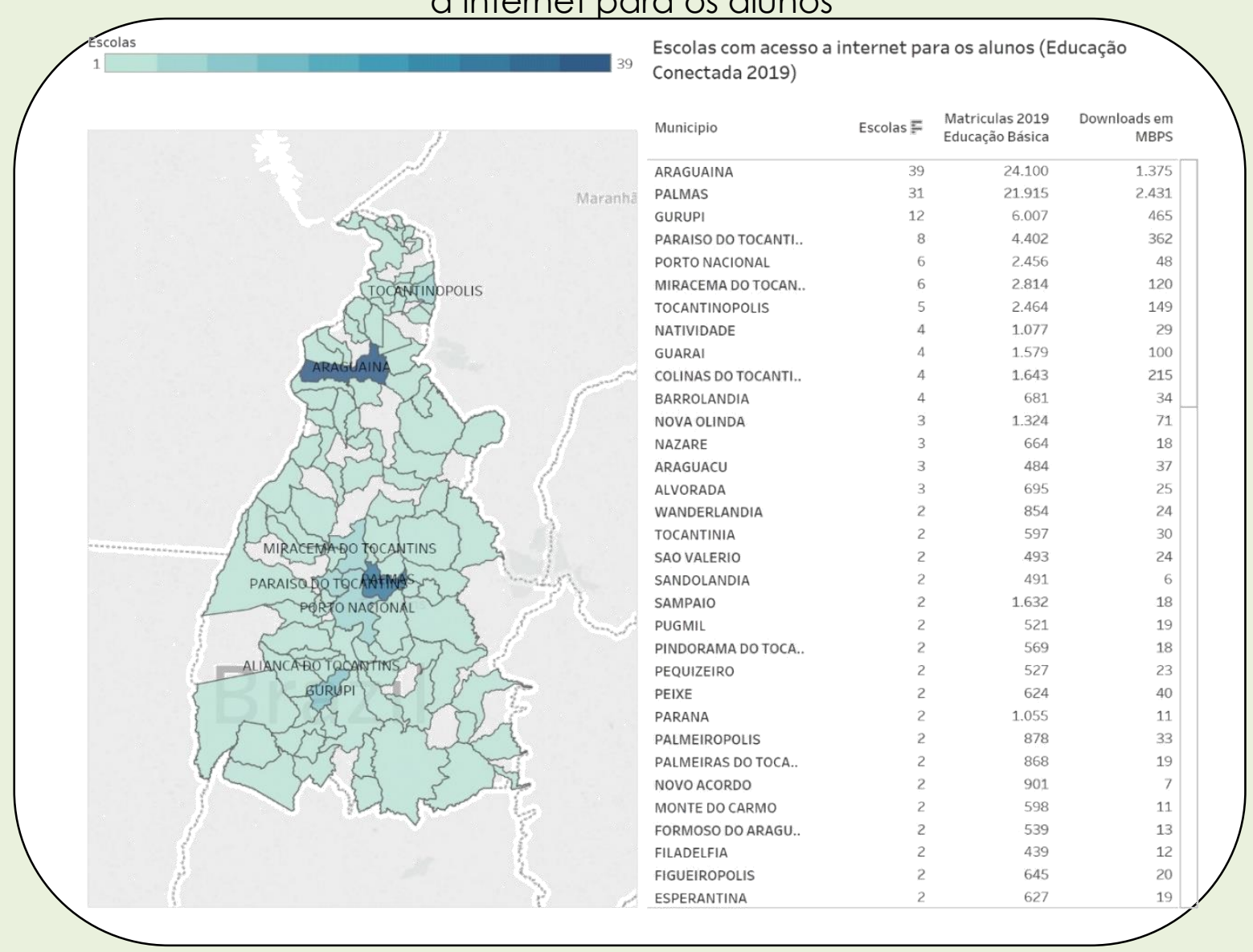

Fonte: Elaborado no software Tableau (TABLEAU, 2021) com os dados do Programa Educação Conectada (MEC, 2021) e divisão municipal do IBGE (2020).

Com base nos dados do Educação Conectada e do Censo Escolar de 2019, das 1.608 escolas de educação básica no Tocantins, cerca de $33 \%$ possuíam acesso à internet. Essas escolas observadas pelo programa Educação Conectada agregam 215.817 matrículas ou 54\% do total de matrículas do Tocantins. A partir desse recorte, detalhando as escolas com acesso à internet disponível para os alunos, são 250 escolas ( $16 \%$ do total) com 112.890 matrículas (28\% do total de matrículas). Na média, no recorte das escolas com algum acesso à internet (250), cerca de metade delas (47\%) disponibilizam acesso à internet para os alunos.

\section{As Ações do Ministério Público do Tocantins durante a pandemia}

Segundo matéria publicada no Portal do Ministério Público do Tocantins (MPTO, 2021) em 4 de fevereiro de 2021, sob o título "MPTO discute estratégias 
para a fiscalização do retorno às aulas presenciais no Estado" informa que os Promotores de Justiça que atuam na área de defesa da educação em todo Estado do Tocantins se reunirão na quarta feira 03 de fevereiro de 2021 para discutir estratégias de atuação voltadas para as ações que visibilizam a retomada das aulas presenciais de forma gradual em todas as unidades do Estado do Tocantins. A matéria esclarece o papel do Ministério Público do Tocantins nesse contexto:

A intenção do Ministério Público do Tocantins (MPTO) é acompanhar as diretrizes dos municípios e promover a fiscalização nas escolas, garantindo que o retorno das aulas em cada unidade escolar aconteça com planejamento individual e atenda aos protocolos sanitários (MPTO, 2021).

O Ministério Público do Estado do Tocantins conta com o apoio do Centro de Apoio Operacional da Infância, Juventude e Educação (CAOPIJE), tendo como objetivo estabelecer uma atuação articulada e estratégica junto do MPTO (MPTO, 2020). De acordo com o Coordenador do CAOPIJE:

... a atuação do Ministério Público será voltada a garantir os direitos fundamentais da saúde e da educação, de forma igualitária, sem que nenhum destes direitos reste prejudicados.

Procedimentos administrativos que formalizem a fiscalização do MPTO no âmbito de cada município deverão ser instaurados. A atuação dos promotores de justiça contará com suporte técnico do CAOPIJE, que visa agilizar os trabalhos e proporcionar uniformidade às ações do Ministério Público.

$\mathrm{Na}$ fiscalização promovida pelas promotorias de justiça, será observado se foram compostas comissões internas nas escolas, capacitados os servidores, planejadas a desinfecção dos ambientes, identificados os profissionais e estudantes do grupo de risco, planejado o uso seguro do transporte escolar e se está sendo acompanhada a situação epidemiológica municipal, entre diversos outros aspectos (MPTO, 2021).

Todas essas ações estão alinhadas ao Decreto n. 6211 que prevê o retorno gradativo das atividades presenciais da educação básica e educação superior no ensino oferecido pelas redes públicas ou particulares em todo o Estado do Tocantins. O decreto autorizado pelo Governo do Estado do Tocantins, autoriza o retorno a retomada das atividades educacionais. "A normativa autoriza esta retomada a partir de 8 de fevereiro e faculta aos estabelecimentos de ensino a oferta de aulas na modalidade não presencial ou no sistema híbrido" (MPTO, 2021). 


\section{A Ações do Centro de Apoio Operacional às Promotorias da Infância, Juventude e Educação (CAOPIJE) durante a pandemia}

No Portal do CAOPIJE (MPTO, 2020) encontramos informações que foram sendo tomadas em função da pandemia intitulado: Educação e Pandemia - Atuação do Ministério Público do Estado do Tocantins. Podemos acompanhar as ações através da linha do tempo:

- Em 21 de julho de 2020 - MPTO cobra plano de ação para retomada das aulas presenciais anunciadas pela SEDUD. Também solicita ao Conselho Estadual de Educação do Tocantins que se manifeste formalmente sobre o retorno das atividades. Segundo informações do Portal as aulas no formato de revezamento estavam previstas para ocorrer a partir de 03 de agosto de 2020 (MPTO, 2020).

- Em 10 de setembro de 2020 - MPTO passou a integrar a rede de colaboração para auxiliar sistemas municipais de educação no Tocantins. Dessa forma, o MPTO10 passou a integrar a Rede de Colaboração Técnica Especializada: formação, monitoramento e avaliação" proposta pela União dos Dirigentes Municipais da Educação do Tocantins (UNDIME/TO) para a gestão da crise e seus efeitos nas redes municipais do Estado. Citando um levantamento realizado pela UNDIME no Estado, quase $60 \%$ dos alunos das redes e sistemas municipais foram considerados em vulnerabilidade social e $75 \%$ deles não tinham acesso à internet/computadores, significando que desde a suspensão das aulas presenciais, encontravam-se sem atividade escolar (MPTO, 2020).

- Em 25 de setembro de 2020 a atuação dos Promotores de Justiça no acompanhamento das políticas educacionais em tempos de pandemia foi tema de um Webinar. Intitulado: $10^{\circ}$ Encontro Operacional com os Promotores de Justiça da Infância, Juventude e Educação. Realizado em 07 de outubro de 2020. A responsabilidade do Poder Público e a atuação do MP: alinhamentos necessários para a garantia do direito à educação no contexto da Pandemia. O objetivo do evento foi subsidiar a atuação das Promotorias de Justiça com atuação na educação para o acompanhamento das políticas educacionais no contexto da Pandemia (MPTO, 2020).

Com base nas informações relativas aos sistemas e redes municipais de ensino do Tocantins em período da Pandemia - COVID 19 organizadas e

10 O Papel do MPTO: ao Ministério Público, por meio da CAOPIJE, caberia o apoio jurídico, o monitoramento das redes e sistemas municipais da educação, além do suporte com a disponibilização de material que vinha sendo produzido, entre outras demandas apontadas pela rede, segundo Denise Soares (MPTO, 2020). 
elaboradas pelo Centro de Apoio Operacional às Promotorias da Infância, Juventude e Educação (CAOPIJE) do Ministério Público do Estado do Tocantins (MPTO), foi possivel realizar uma análise preliminar e sucinta sobre aspectos da Pandemia no Estado em um recorte dos meses de junho e agosto de 2020, com vistas a compreender os impactos da COVID na educação.

FIGURA 2 - Repartição dos municípios por sistema próprio de ensino.

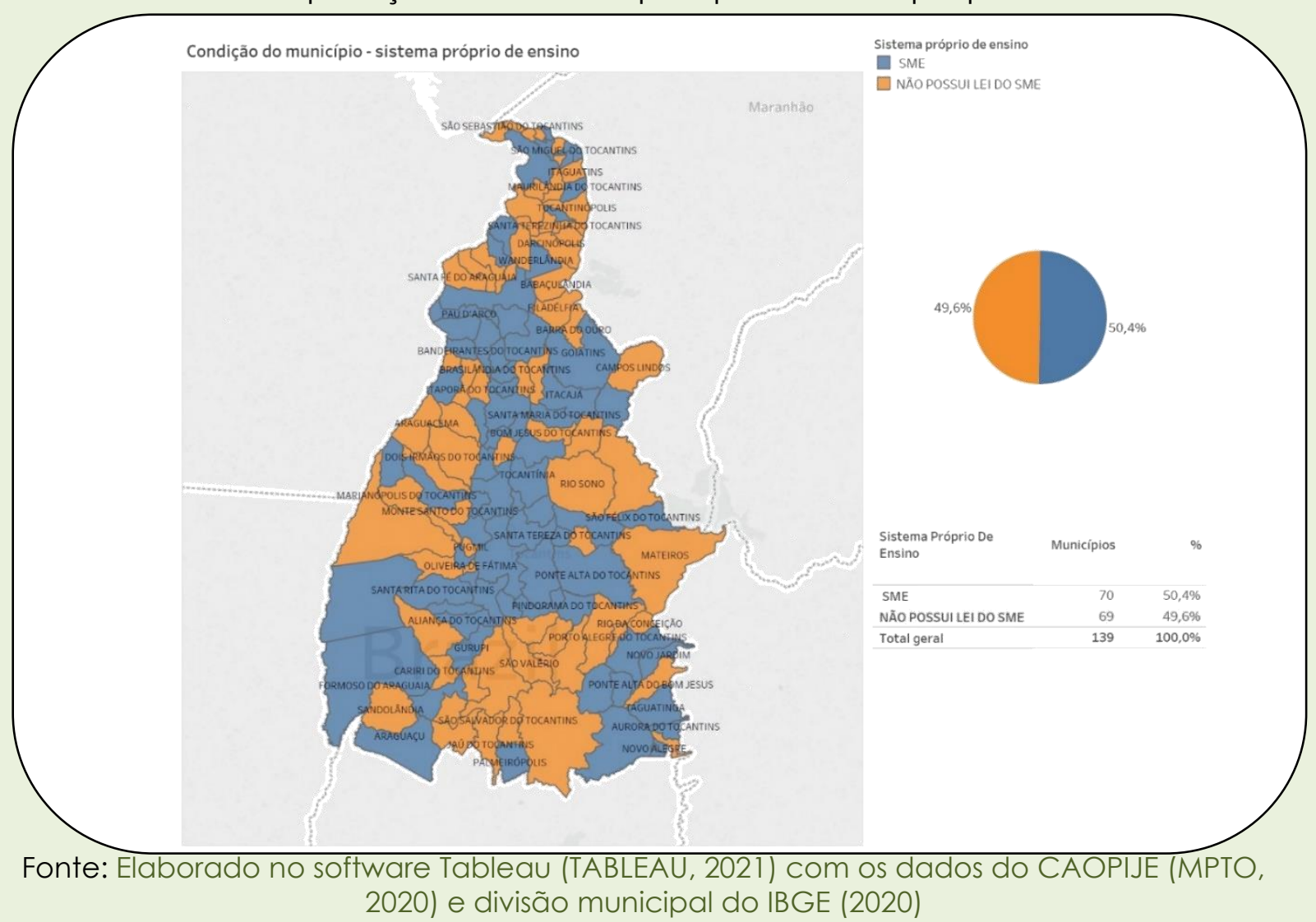

O CAOPIJE utilizou as seguintes fontes para elaborar esses dados: Censo Escolar/IBGE, Qedu.com, Censo Demográfico 2010, Relatório SIAFI TCETO/201911, Controle da Undime, Relatórios de repasses do FUNDEB, Centro de Informações Estratégicas de Vigilância em Saúde / SES-TO'2 e Governo do

\footnotetext{
${ }^{11}$ BRASIL. Relatório SIAFI TCE-TO/2019. Disponível em: http://sisweb.tesouro.gov.br. Acesso em: 27 jul. 2021.

${ }^{12}$ TOCANTINS. Centro de Informações Estratégicas de Vigilância em Saúde / SES-TO. Disponível em: http://integra.saude.to.gov.br/covid19/InformacoesEpidemiologicas Acesso em: 27 jul. 2021.
} 
Tocantins ${ }^{13}$. Sobre o sistema próprio de ensino no Estado do Tocantins, dos 139 municípios, cerca de metade (69) não possui a lei do Sistema Municipal de Ensino (SME). Para o período de junho a agosto de 2020, o CAOPIJE/MPTO realizou nos 139 municípios um levantamento sobre a situação das atividades remotas da educação. Mais da metade dos municípios $157,6 \%$ ou 80 municípios) já havia iniciado as atividades remotas em junho e 19,4\% iniciariam suas atividades em julho de 2020 e 5,0\% em agosto de 2020, perfazendo um total de 114 municípios ou $82 \%$. Somando mais $14,4 \%$ que ainda estavam planejando as atividades, o total de municípios chega a $96,4 \%$. Apenas $3,6 \%$ (5 municípios: Buriti do Tocantins, Babaçulandia, Cristalândia, Formoso do Araguaia e Talismã) não farão atividades remotas.

FIGURA 3 - Repartição dos municípios do Tocantins por situação das atividades remotas durante a pandemia.

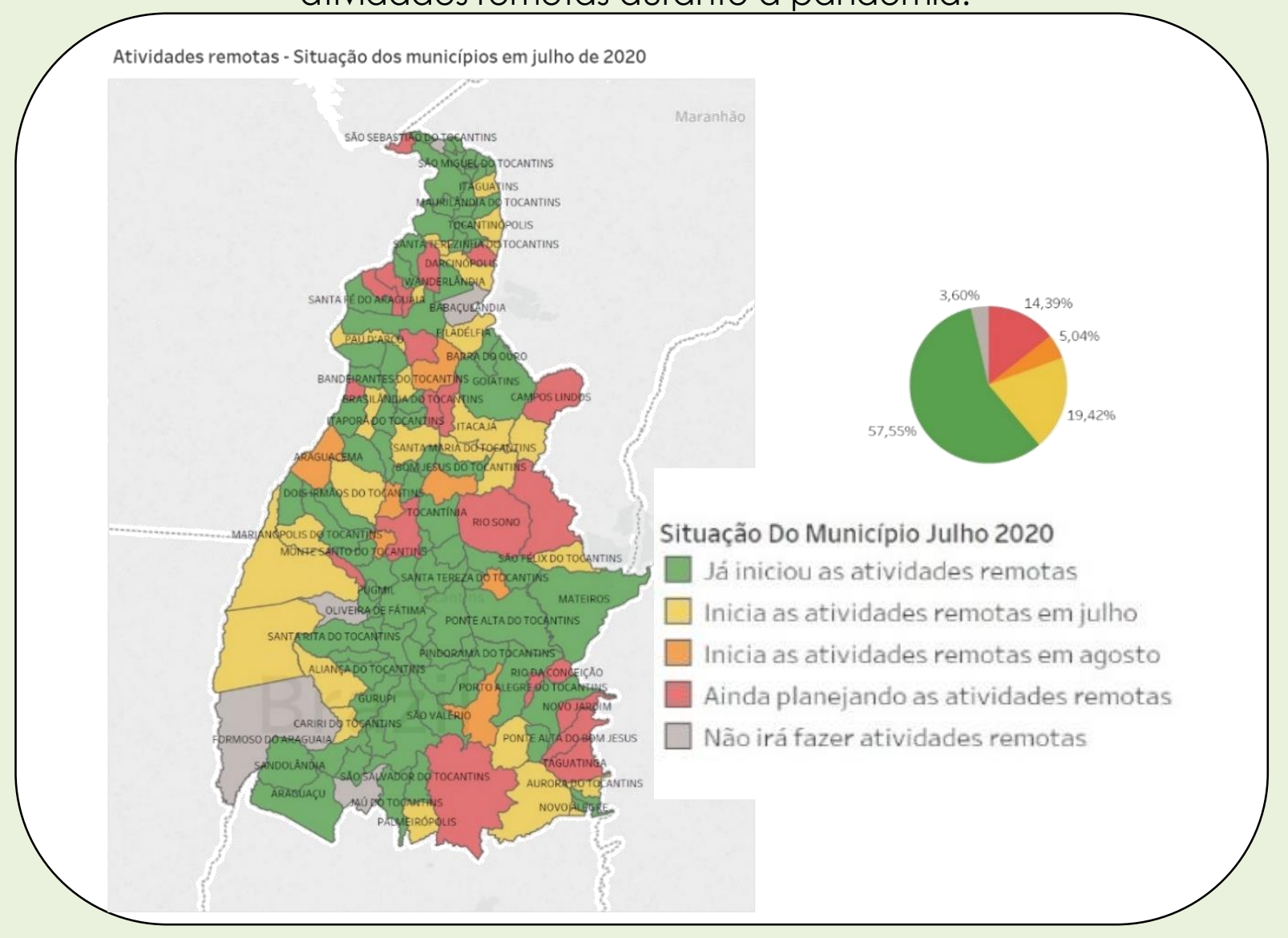

Fonte: Elaborado no software Tableau (TABLEAU, 2021) com os dados do CAOPIJE (MPTO, 2020) e divisão municipal do IBGE (2020)

${ }^{13}$ TOCANTINS. Dados do Estado. Disponível em: https://central3.to.gov.br/arquivo/510155/ Acesso em: 27 jul. 2021. 
Sobre os casos e óbitos de Covid 19, o CAOPIJE fez um recorte aproximado de 1 mês entre as datas de 21/07/2020 e 26/08/2020 para estimar a evolução da pandemia nos municípios do Tocantins. Os municípios que concentraram mais casos em valores absolutos foram Palmas e Araguaína, juntos com cerca de 9 mil casos no início do período e chegando a 22 mil no final do período. Palmas triplicou o número de casos e Araguaína dobrou. Gurupi, Porto Nacional, Colinas do Tocantins e Paraíso dos Tocantins tiveram saltos nos números de casos, chegando a valores superiores a mil.

FIGURA 4 - Comparação dos casos de Covid 19 pela repartição dos municípios do Tocantins no período entre 21/07/2020 e 26/08/2020.

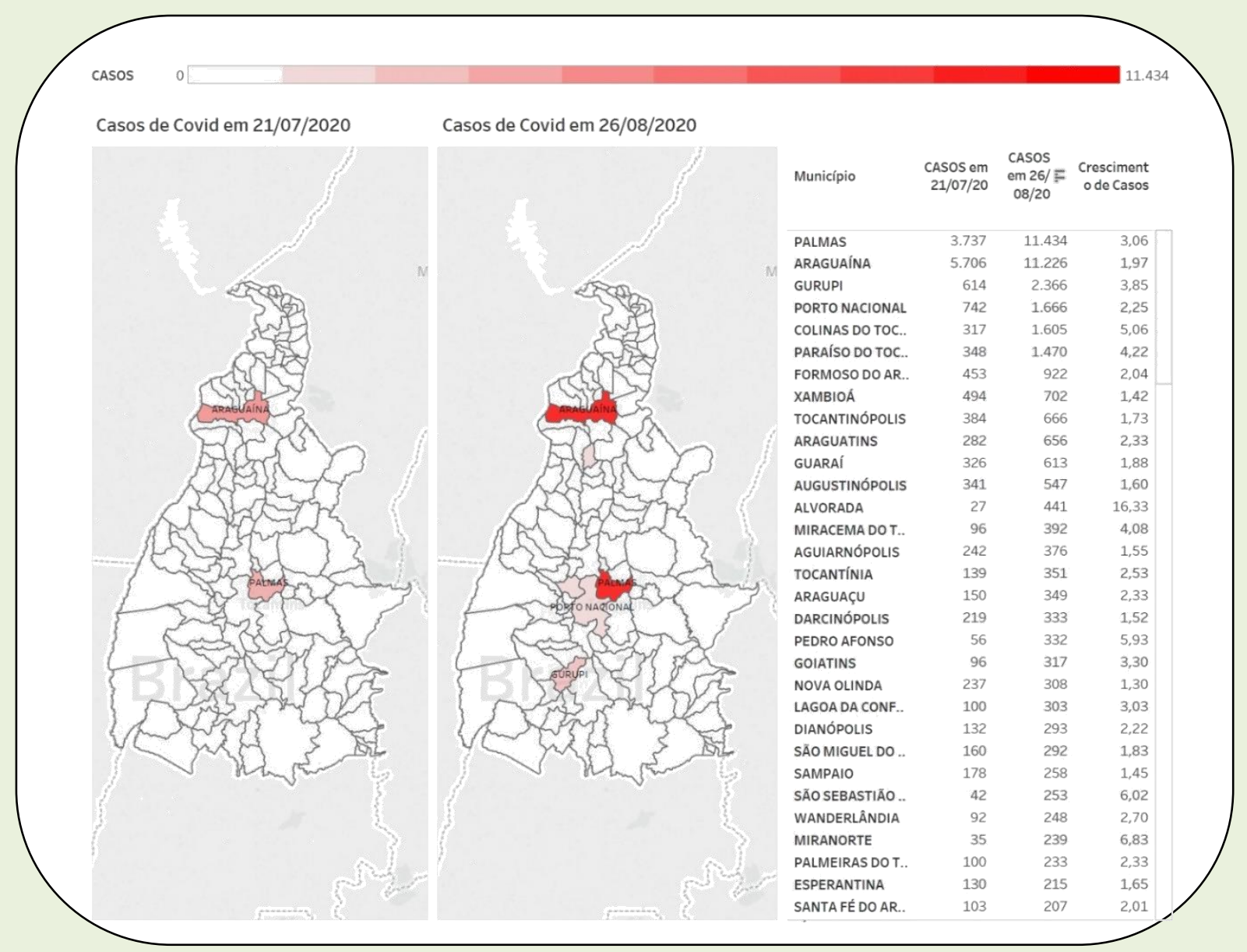

Fonte: Elaborado no software Tableau (TABLEAU, 2021) com os dados do CAOPIJE (MPTO, 2020) e divisão municipal do IBGE (2020). 
Sobre os óbitos, a tendência foi de acompanhar as quantidades de casos de COVID. Araguaína e Palmas concentraram os óbitos no período, iniciando juntos com 107 e chegando a 221 no final do período.

FIGURA 5 - Comparação dos óbitos de Covid 19 pela repartição dos municípios do Tocantins no período entre 21/07/2020 e 26/08/2020.

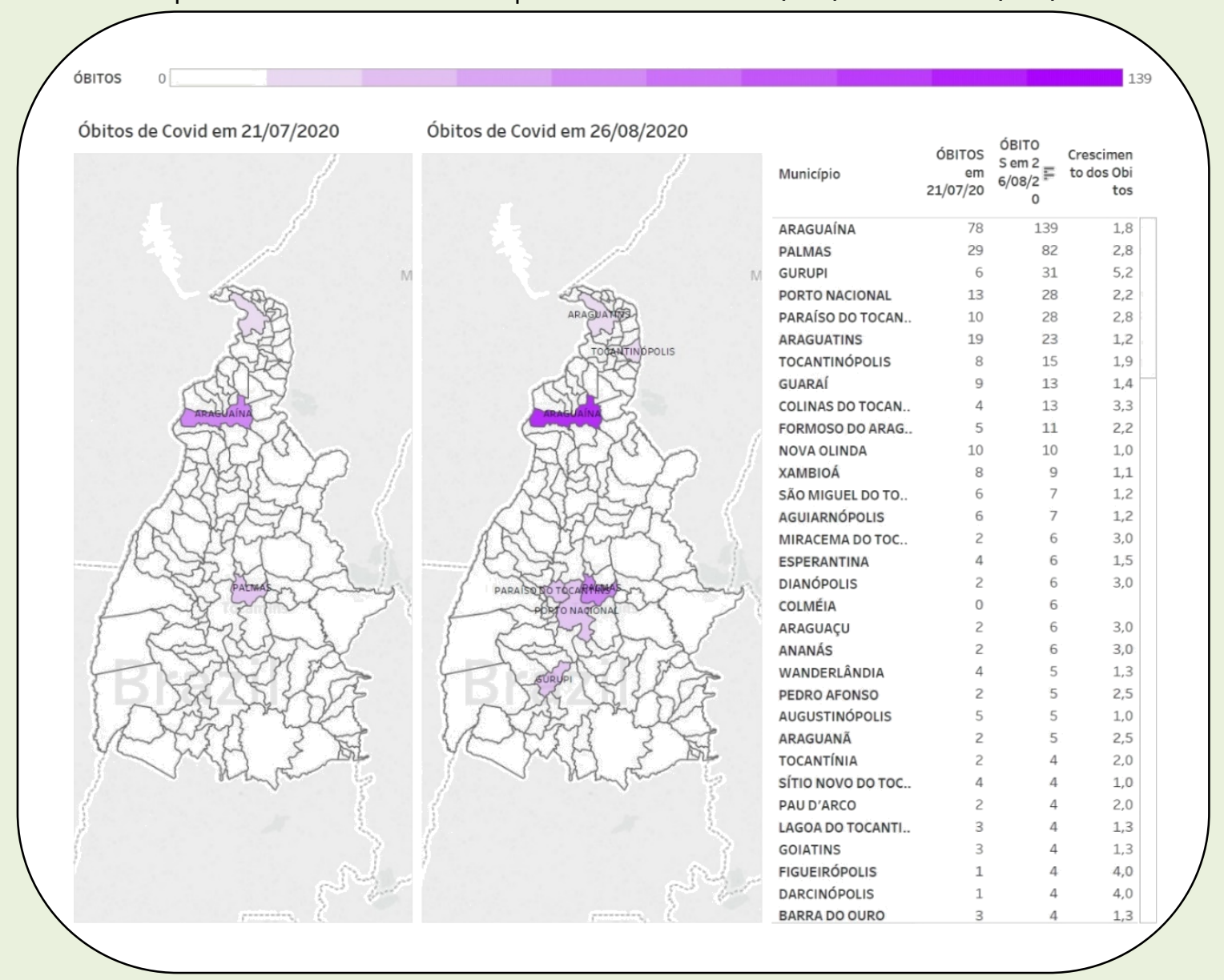

Fonte: Elaborado no Elaborado no software Tableau (TABLEAU, 2021) com os dados do CAOPIJE (MPTO, 2020) e divisão municipal do IBGE (2020).

Em termos proporcionais, destaca-se Gurupi, que quadruplicou os casos (614 para 2.366) e multiplicou por 5 os óbitos (6 para 31).

Retomando as informações de sistema próprio de ensino, escolas com acesso à internet para alunos e situação de atividades remotas, esses 6 municípios com mais casos de Covid 19 no período possuíam sistema próprio, escolas com internet e já estavam realizando atividades remotas. 


\title{
A Ações da Rede de Colaboração Técnica Especializada: Formação, Acompanhamento e Avaliação - Rede ColaborAção Tocantins (RCT) durante a pandemia
}

Foi elaborado o documento "Gestão da Educação na Conjuntura da Pandemia: com as palavras, cursistas e formadores" que trata da Rede ColaborAção Tocantins (RTC). Nas "Palavras Iniciais" do documento são apresentados os objetivos da rede.

\begin{abstract}
A Rede de Colaboração Técnica Especializada: Formação, Acompanhamento e Avaliação - Rede ColaborAção Tocantins (RCT) tem por objetivo apoiar as redes e os sistemas municipais de ensino / educação do Estado do Tocantins no enfrentamento da crise educacional derivada da pandemia da Covid-19, notadamente, em relação à sistematização da oferta educacional durante o período da pandemia e no processo de retomada das atividades educacionais, por meio de formação, acompanhamento e avaliação dos processos de gestão, ensino e aprendizagem (LAGARES, 2020).
\end{abstract}

Nesse sentido foi apresentado o segundo caderno Educação Municipal - "Gestão da educação na conjuntura da pandemia: com as palavras, cursistas e formadores" da série de publicações da RCT voltadas para à formação, acompanhamento e avaliação das ações das redes e sistemas de ensino/educação. A proposta do caderno é ser uma referência para todos os profissionais da educação municipal, apresentando discussões e orientações relativas a sistematização da oferta educacional no contexto da pandemia, especialmente, no que tange à validação das atividades remotas, a finalização e regularização do ano letivo de 2020 e o processo de retomada das atividades educacionais em 2021. O documento reitera a grave crise evidenciada pela pandemia no contexto educacional e os desafios e incertezas que precisam ser debatidos e discutidos com toda a comunidade escolar. E complementa,

Por fim, reitera-se que a pandemia do coronavírus evidenciou uma forte crise, dentre outras, da escolarização. Em certos momentos, como agora, aproveitamos para discutir concepções de educação, escola, aprendizagem, avaliação ... não apenas modos de fazer. Aproveitamos para reforçar as ideias daqueles que defendem as dimensões públicas da escola. Aproveitamos para retirar das experiências da pandemia, desse tempo triste, a oportunidade pedagógica, para não ficarmos na retaguarda - Rede Colaboração Tocantins (LAGARES, 2020). 
O documento buscou trabalhar muitas das questões que são desafiadoras no âmbito dos municípios tocantinenses. Foram trabalhadas diversas questões levantadas pelos cursistas e formadores e buscou-se discutir na busca de compreensão da realidade educacional. Para tanto foram trabalhadas diversas questões voltadas tanto para as normativas legais como para o papel a ser desempenhados nas redes de ensino e sistemas de ensino do Estado do Tocantins. Foram abordados no documento: o Comitê Municipal de Enfrentamento da Crise Educacional; os papéis a serem desempenhados por Dirigentes Municipais e pela Secretaria Municipal de Educação; a necessidade do monitoramento das ações voltadas para o acompanhamento do Plano Municipal de Educação (PME) durante o período da pandemia; o encerramento do ano letivo de 2020; a questão da evasão escolar ocorrida durante a pandemia; as responsabilidades do Estado; as questões da avaliação; os municípios que possuem sistemas de educação e dos municípios que integram o SEE/TO; o importante papel dos Conselhos Municipais de Educação (CMEs); as questões referentes ao currículo, ensino e aprendizagem, avaliação, aprovação, reprovação durante a pandemia; as atividades remotas; a mudança na gestão educacional ocasionada pelas eleições municipais ocorridas em 2020 e o planejamento escolar para o ano de 2021. Todas essas questões visam auxiliar os municípios Tocantinenses tendo por base o apoio da Rede ColaborAção Tocantins.

No que diz respeito ao Comitê Municipal de Enfrentamento da Crise Educacional, o documento parte da base legal para orientar prefeitos e Secretaria Municipal de Educação para a elaboração da Portaria de criação do Comitê Municipal de Enfrentamento da Crise Educacional. Cita a LDB n. ${ }^{\circ}$ 9394/1996 que em seu artigo 11 esclarece "Art. 11 - os Municípios incumbir-seão de: I organizar, manter e desenvolver os órgão e instituições oficiais dos seus sistemas de ensino, integrando-os às políticas e planos educacionais da União e dos Estados". Ressalta o documento: "é importante atentar que o ato de composição do Comitê de Enfrentamento é vinculado à organização da administração municipal, portanto, independentemente de o município ser rede ou sistema de educação/ ensino, será a Secretaria de Educação, 
enquanto órgão executivo, quem tem a atribuição de organizar a oferta educacional" (LAGARES, 2020).

Outro ponto destacado foi o levantamento das ações realizadas no monitoramento do Plano Municipal de Educação (PME) durante o ano de 2020. O documento lembra que o PME é uma lei que deve ser cumprida em um período de dez anos, com a intenção de gerar políticas públicas educacionais e por esse motivo, trata-se fundamental ser uma referência para a gestão da educação municipal. Para tanto, o Dirigente Municipal de Educação deverá organizar um relatório de monitoramento do PME apresentando as ações que foram tomadas, os impactos da pandemia nas ações previstas no plano. Fazer o levantamento se haverá necessidade de rever metas e estratégias. Enfim avaliar o andamento do PME e a necessidade de readaptação diante dos prazos previstos para o cumprimento das mesmas. O relatório de monitoramento deverá, portanto, observar os impactos da pandemia na orientação para a transição da gestão municipal e sugere a atenção em buscar responder as seguintes questões: Quais foram os avanços e conquistas da educação no município? Quais metas e estratégias não puderam ser atingidas e por quais motivos? Qual histórico do trabalho será repassado para a equipe que assume a secretaria nos próximos anos, a partir de 2021? (LAGARES, 2020).

Portanto, a mudança na gestão educacional ocasionada pelas eleições municipais ocorridas em 2020 é outro ponto que irá demandar atenção dos atuais dirigentes municipais. Considerando a importância de informar as novas gestões, quando for esse o caso do município, onde houve mudanças dos dirigentes, do período atípico que foi ao ano de 2020. Dessa forma o documento orienta os dirigentes municipais que as informações elaboradas pelas equipes das Secretarias Municipais de Educação deverão ser acrescentadas as informações e dados referentes ao enfrentamento da crise educacional e explicita as recomendações que precisam constar. Tais como: o diagnóstico proposto pela RCT; as Resoluções publicadas pelo CME; as Atas de audiências públicas realizadas; os calendários escolares elaborados ao longo de 2020; a proposta pedagógica adotada no período 
da pandemia; o plano de retomada das atividades presenciais/híbridos adotados; o levantamento de todos os procedimentos e processos realizadas de aquisições de itens para a retomada das atividades presenciais no município; a descrição dos níveis de aprendizagem e situação sócio educacional dos alunos; os documentos utilizados para a validação das atividades remotas ofertadas durante o período de pandemia; os atos de composição e atuação do Comitê de Enfrentamento da Crise Educacional e por fim acrescentar os relatórios de Monitoramento e Avaliação do PME durante o ano de 2020 (LAGARES, 2020).

Considerando o planejamento escolar para o ano de 2021 inúmeros são dos desafios. Além da organização, execução, acompanhamento e avaliação das atividades escolares, será necessário acrescentar a atenção para a avaliação do período em que as escolas ficaram fechadas, os impactos na suspensão das aulas presenciais. A necessidade de um diagnóstico cuidadoso e detalhado para se ter por base as ações a serem adotadas a partir do ano letivo de 2021. Lagares, 2020 chama a atenção a necessidade de observar todo arcabouço legal-administrativo que foi sendo implementado ao longo de 2020 e destaca: a atenção a Constituição Federal de 1988 nos artigos que tratam da educação, a LDB n. ${ }^{\circ}$ 9394/1996, os respectivos PMEs, os atos normativos emitidos pelo CNE, CEE e CME, a atenção ao Guia de Implementação de Protocolos de Retorno das Atividades Presenciais nas Escolas de Educação Básica, elaborado pelo Ministério da Educação (MEC), a observação dos Protocolos de Segurança em Saúde para o retorno das atividades educacionais presenciais do Estado do Tocantins, além de todos os cuidados e atenção as dimensões pedagógicas locais (LAGARES, 2020).

Grande parte dos problemas que foram ressaltados durante a pandemia já fazem parte de pesquisas e são preocupações conhecidas por pesquisadores que buscam compreender as políticas educacionais e visam pensar uma avaliação da educação brasileira que seja diagnóstica, qualitativa, real e que considere as especificidades, as inúmeras realidades que a população que depende da educação pública, gratuita e laica está 
submetida de fato. Podemos citar entre eles a questão da evasão escolar, o abandono escolar que obviamente foram impactados com a pandemia. De repente a escola deixou de ser acessível para uma parcela desses sujeitos, o acompanhamento das atividades escolares se tornou inviáveis diante das inúmeras dificuldades apontadas ao longo deste texto. Falta de celular, falta de internet, falta de computador, falta de água enganada, falta de alimento e junto o medo da fome e da incerteza da vida. Esses sujeitos precisam ser considerados, precisam ser levantados pelas escolas, precisam ser devidamente avaliados e pensadas estratégias para suprir as perdas que foram inúmeras e desastrosas.

Observamos, olhando para o Estado do Tocantins a importância do trabalho de diferentes segmentos atuarem juntos e buscarem alternativas para tantos problemas. Foram citados os papeis significativos do Ministério Público do Estado do Tocantins, do Conselho Estadual de Educação, da UNDIME do Estado do Tocantins, das Secretarias Municipais de Educação dos municípios que compõem o Estado do Tocantins e da importância da atuação dos Conselhos Municipais de Educação no acompanhamento, monitoramento e validação dos instrumentos que embasaram o ano de 2020. Mas é importante lembrar da importância da escuta de toda comunidade escolar, de alunos, pais, professores, funcionários que contemplam esse universo. Só através do envolvimento de todos será possível pensar alternativas viáveis para sanar os problemas que precisam de vontade política e ações coerentes com o compromisso do direito a educação.

\section{CONSIDERAÇÕES FINAIS}

Muito há que se pesquisar sobre o ano letivo de 2020 e somente com o tempo poderemos ir avaliando as reais consequências da pandemia em todo cenário da educação brasileira. Sabemos que a qualidade da educação envolve diversos fatores que precisam ser considerados tais como os aspectos econômicos, políticos, sociais, culturais e uma série de fatores que estão dentro da escola e fora dela. A pandemia entre todos os impactos enfatizou muitos deles e trouxe à tona uma realidade que até então ficava escondida 
sem grande atenção, a questão da enorme desigualdade social, a falta de acesso a uma educação de qualidade que temos no País como um todo. A pandemia nos fez lembrar da fragilidade do direito à educação de milhares de brasileiros, da omissão do dever do Estado na garantia de uma educação para todos. O Estado do Tocantins trabalhado neste artigo já aponta para uma serie de investigações possíveis, no âmbito de acompanhar as ações de fato implementadas. Pesquisas in loco poderão se somar a acompanhar o desenvolvimento de ações voltadas a sanar os problemas que a pandemia aflorou não só no Estado do Tocantins como em todo o Brasil.

Em termos de ações normativas podemos aferir que o Estado do Tocantins se implementou diversas ações no combate a pandemia. A principiou atuou na organização das ações necessárias e procurou atentar para a realidades dos municípios. De forma articulada com o Ministério Público, com o Conselho Estadual de Educação e a Undime uma série de documentos foram elaboradas na tentativa da compreensão, formação e atenção a todos os aspectos que de forma direta ou indireta impactaram a educação no Estado. Já como interpretou a Pandemia no estado e nos seus municípios serão necessárias outras pesquisas. Podemos constatar uma série de estudos e expectativas de ações a serem implementadas.

\section{AGRADECIMENTOS}

OS autores agradecem ao CNPq e à FAPEMIG pelo apoio concedido para realização da pesquisa. Também agradecem à Faculdade de Educação da Unicamp pela estrutura oferecida.

\section{REFERÊNCIAS}

CARVALHO, L.; PIRES, L. N.; XAVIER, L.L. COVID-19 e desigualdade no Brasil. Experiment Findings April 2020, p.1-3. DOI: 10.13140/RG.2.2.27014.73282.

FIGUEIREDO SANTOS, J. A. Covid-19, causas fundamentais, classe social e território. Trabalho, Educação e Saúde, Rio de Janeiro, v. 18, n. 3, 2020. IBGE. Estrutura Territorial. 2020. Disponível em: https://www.ibge.gov.br/ geociencias/organizacao-do-territorio/estrutura-territorial.html. Acesso em: 27 jul. 2021. 
INEP. Censo Escolar. 2021. Disponível em https://www.gov.br/inep/ptbr/acesso-a-informacao/dados-abertos/sinopses-estatisticas. Acesso em: 27 jul. 2021.

LAGARES. R. (Org.) Gestão da educação na conjuntura da pandemia: com a palavra, cursistas e formadores. Palmas, TO: Universidade Federal do Tocantins, 2020.

MEC. Medidor Educação Conectada. 2021. Disponível em http://medidor.educacaoconectada.mec.gov.br/mapa-escola/?regiao= NORTE\&estado=TO\&inep=. Acesso em: 27 jul. 2021.

MPTO. MPTO discute estratégias para a fiscalização do retorno às aulas presenciais no Estadoa. 2021. https://www.mpto.mp.br/portal/2021/02/03/ mpto-discute-estrategias-para-a-fiscalizacao-do-retorno-as-aulas-presenciaisno-estado

MPTO. Educação e Pandemia. 2020. Disponível em https://mpto.mp.br/caopda-infancia-e-juventude/2020/1 1/23/educacao-e-pandemia-atuacao-doministerio-publico-do-estado-do-tocantins. Acesso em: 27 jul. 2021.

TABLEAU. Software de análise e business intelligence. Disponível em: https://www.tableau.com/pt-br. Acesso em: 27 jul. 2021.

TOCANTINS. Boletim Epidemiológico: Notificações para Covid-19. 17 de janeiro de 2021, Nº 308. Disponível em:

https://central3.to.gov.br/arquivo/547822/. Acesso em: 27 jul. 2021.

TOCANTINS. Governo do Estado do Tocantins. 2020. Disponível em: https://seduc.to.gov.br/. Acesso em: 27 jul. 2021.

Recebido em: 21 de setembro de 2021.

Aprovado em: 21 de novembro de 2021.

Publicado em: 23 de novembro de 2021. 